\section{MONOGRAF \\ TINDAKAN NON FARMAKOLOGIS ATASI DISMENORHOE REMAJA}

Buku Monograf ini berisi Metode penanganan Dismenorhoe non Farmakologis yang dapat dilakukan secara mandiri oleh remaja. Tindakan non Faramakologis yang dimaksud yaitu Kompres Hangat dan Massage Endorphine yang terbukti lebih efektif mengurangi nyeri haid jika dilakukan secara bersamaan dengan menerapkan Standar Operasional Prosedur (SOP) Tindakan Kompres Hangat dan Massage Endorphine secara benar dan tepat.

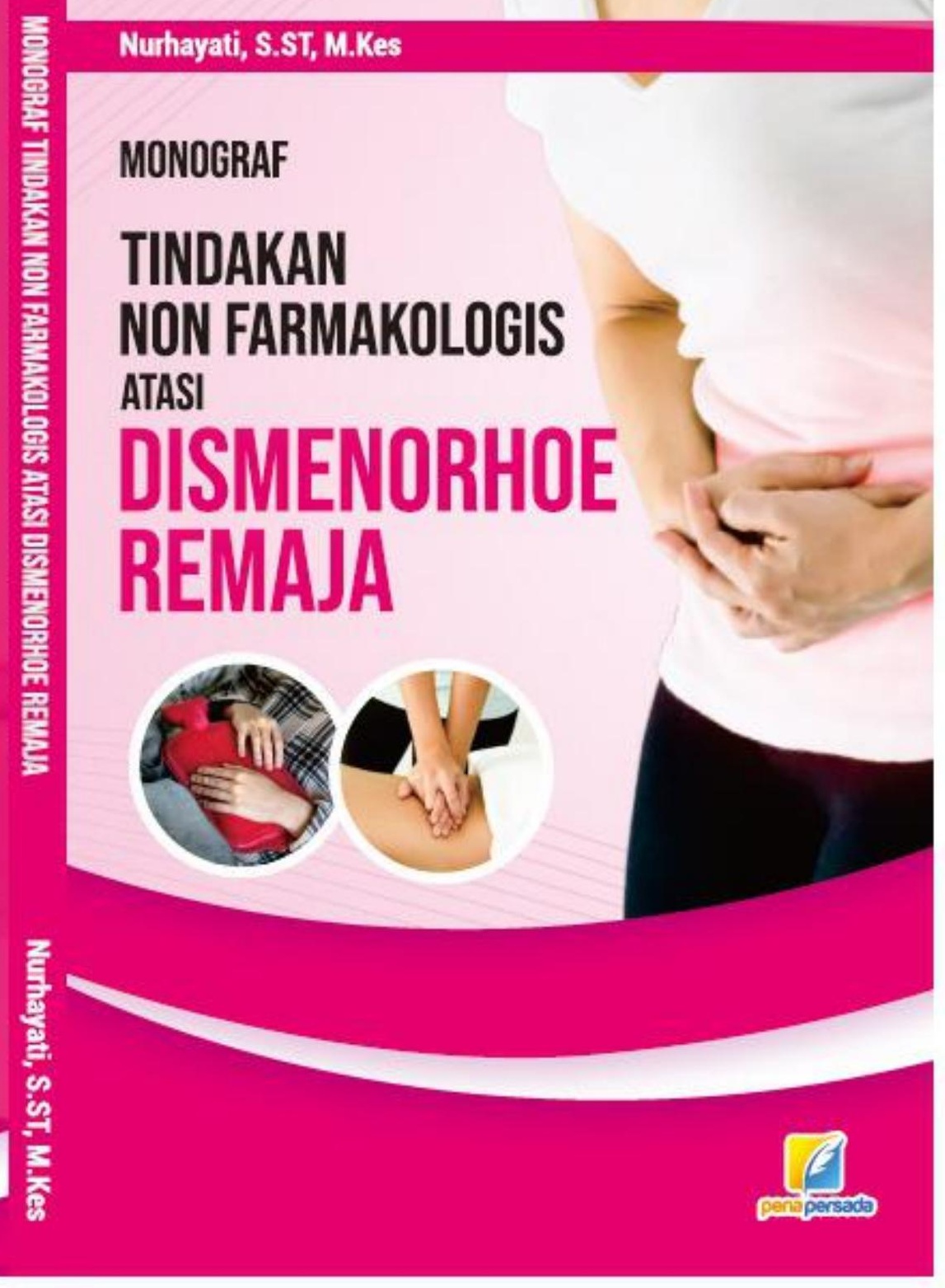




\title{
MONOGRAF \\ TINDAKAN NON FARMAKOLOGIS ATASI DISMENORHOE REMAJA
}

\author{
Nurhayati, S.ST, M.Kes
}

\section{7 \\ penapersada}

PENERBIT CV. PENA PERSADA 


\title{
MONOGRAF \\ TINDAKAN NON FARMAKOLOGIS ATASI DISMENORHOE REMAJA
}

\author{
Penulis: \\ Nurhayati, S.ST, M.Kes \\ ISBN : 978-623-315-234-1 \\ Design Cover : \\ Retnani Nur Briliant \\ Layout : \\ Hasnah Aulia \\ Penerbit CV. Pena Persada \\ Redaksi : \\ Jawa Tengah \\ Email : penerbit.penapersada@gmail.com \\ Anggota IKAPI \\ All right reserved \\ Cetakan pertama : 2021
}

Jl. Gerilya No. 292 Purwokerto Selatan, Kab. Banyumas

Website : penapersada.com Phone : (0281) 7771388

Hak Cipta dilindungi oleh undang-undang. Dilarang memperbanyak karya tulis ini dalam bentuk apapun tanpa izin penerbit 


\section{KATA PENGANTAR}

Syukur Alhamdulillah pada akhirnya monograf dengan judul "Tindakan Nonfarmakologis Dismenorhoe Remaja" ini dapat diselesaikan pada waktunya. Sebagai hasil penelitian, monograf ini membahas Tindakan non farmakologis mandiri yakni massage endorphine dan kompres hangat yang dapat dilakukan oleh remaja putri dalam mengatasi keluhan nyeri haid yang dirasakan tanpa harus secara farmakologis ataupun menggunakan obatobatan. Metodologi penelitian yang digunakan dalam penelitian ini adalah Penelitian ini menggunakan metode eksperimen dengan desain quasi experiment tanpa kelompok kontrol dengan pendekatan one group pretest posttest desain yang bertujuan untuk mengetahui gejala atau pengaruh yang timbul sebagai akibat dari adanya perlakuan tertentu atau ekperimen tersebut, ciri khusus dari penelitian eksperimen ini berupa perlakuan atau intervensi terhadap suatu variabel. Dari perlakuan tersebut diharapkan terjadi perubahan atau pengaruh terhadap variabel yang lain. Kesimpulan penelitian ini adalah, diperoleh perbedaan intensitas nyeri sebelum dan sesudah kompres hangat dan massage endorphine sehingga dapat disimpulkan bahwa tindakan kompres hangat dan massage endorphine berpengaruh dapat menurunkan intensitas nyeri haid (Dismenorhoe) pada Mahasiswi. Salah satu cara penatalaksanaan nonfarmakologis untuk mengurangi nyeri menstruasi dengan manajemen sentuhan yaitu pijat endorphine. Pijat Endorphine merupakan sebuah terapi sentuhan/pijatan ringan yang cukup penting diberikan pada wanita yang mengalami nyeri. Hal ini disebabkan karena pijatan merangsang tubuh untuk melepaskan 
senyawa Endorphine yang merupakan pereda rasa sakit dan dapat menciptakan perasaan nyaman. Pemberian kompres hangat merupakan salah satu tindakan mandiri. Efek hangat dari kompres dapat menyebabkan vasodilatasi pada pembuluh darah yang nantinya akan meningkatkan aliran darah ke jaringan Penyaluran zat asam dan makanan ke sel-sel diperbesar dan pembuangan dari zat-zat diperbaiki yang dapat mengurangi rasa nyeri haid. Data yang digunakan dalam penelitian ini berasal dari berbagai sumber dan diperoleh melalui observasi di lapangan, studi literatur, dan dokumentasi dari berbagai sumber. Sesuai namanya, monograf ini menyimpan harapan agar remaja putri dapat mengaplikasikan tindakan massage endhorphine dan kompres hangat ini secara mandiri ketika mengalami dismenohoe sehingga tidak lagi menjadi penghalang mereka untuk beraktivitas dan harus menggunakan analgesik yang akan berdampak ketagihan dan akan memberikan efek samping obat yang berbahaya bagi pasien. Dengan ini juga maka memberikan peluang pada remaja untuk dapat mengambangkan kreativitasnya dalam pendidikan tanpa harus terhalang oleh keluhan nyeri haid. Selamat membaca.

Makassar, 04 Maret 2021 


\begin{abstract}
ABSTRAK
Dismenore merupakan gangguan menstruasi yang sering dialami oleh remaja putri. Secara umum penanganan nyeri dismenore terbagi dalam dua kategori yaitu pendekatan farmakologis dan non farmakologis. Secara non farmakologik antara lain kompres hangatdan endorphine massage. Penelitian ini bertujuan untuk mengetahui pengaruh pemberian pemberian kompres hangat dan endorphine massage terhadap kejadian dismenore pada mahasiswi. Terdapat pengaruh pemberian kompres hangat dan massage endorphine terhadap penurunan nyeri haid (dismenorhoe) pada mahasiswi.
\end{abstract}

Kata Kunci : Dismenore, kompres hangat, endorphine massage 


\section{DAFTAR ISI}

KATA PENGANTAR …................................................... ii

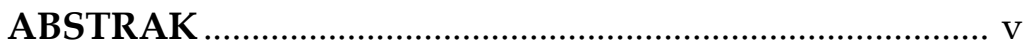

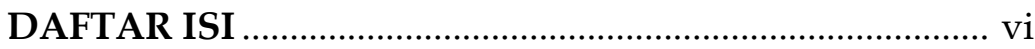

BAB I PENDAHULUAN .................................................... 1

BAB II TINJAUAN PUSTAKA ……................................. 5

BAB III HASIL DAN PEMBAHASAN ............................ 23

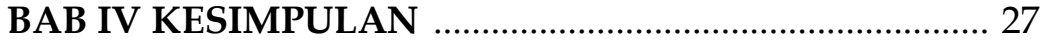

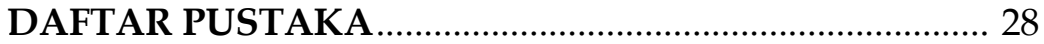

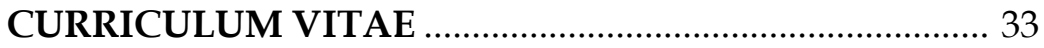

SURAT PERNYATAAN BERSEDIA

MENJADI RESPONDEN .................................................... 35 


\section{BAB I \\ PENDAHULUAN}

Perubahan paling awal muncul pada remaja ditandai dengan adanya perkembangan secara biologis. Salah satu tanda keremajaan wanita secara biologi dimulainya remaja mengalami menstruasi. Menstruasi dimulai saat pubertas dan kemampuan seorang wanita untuk mengandung anak atau masa reproduksi. Ketika menstruasi tiba, ada kalanya terdapat kelainan atau gangguan yang ada hubungan dengan menstruasi diantaranya premenstrual tension (ketegangan sebelum haid), mastodinia, mittelschmerz (rasa nyeri saat ovulasi) dan dismenore (rasa nyeri saat menstruasi) (Manuaba, 2010).

Dismenore merupakan gangguan menstruasi yang sering dialami oleh remaja putri. Dismenorea ditandai dengan nyeri perut bagian bawah dan dapat disertai dengan gejala gejala lainnya. Sebagian besar nyeri haid terjadi saat usia remaja dan dapat menimbulkan dampak konflik emosional, ketegangan dan kegelisahan. Akibat dismenore mereka bahkan tidak dapat pergi kesekolah, aktivitas belajar dalam pembelajaran terganggu, konsentrasi menjadi menurun bahkan tidak ada sehingga materi yang diberikan selama pembelajaran yang berlangsug tidak bisa ditangkap oleh remaja yang sedang mengalami dismenorea (Made Lestari, 2013).

Angka kejadian nyeri haid di dunia sangat besar, ratarata lebih dari 50\% perempuan disetiap negara mengalaminya (Abidin, 2005 dalam Ulfa, 2015). Menurut 
data dari WHO didapatkan kejadian sebesar 1.769.425 jiwa (90\%) wanita yang mengalami dismenore dengan 10-15\% mengalami dismenore berat (Info Sehat, 2010). Prevalensi dismenore di Indonesia tahun 2008 sebesar 64,25\% yang terdiri dari 54,89\% dismenore primer dan 9,36\% dismenore sekunder (Santoso, 2008 dalam Ulfa, 2015).

Secara umum penanganan nyeri dismenore terbagi dalam dua kategori yaitu pendekatan farmakologis dan non farmakologis. Secara farmakologis nyeri dapat ditangani dengan terapi analgesik yang merupakan metoda paling umum digunakan untuk menghilangkan nyeri. Walaupun analgesik dapat menghilangkan nyeri dengan efektif, namun penggunaan analgesik akan berdampak ketagihan dan akan memberikan efek samping obat yang berbahaya bagi pasien. Secara non farmakologik antara lain kompres hangat, massage endorphine, teknik relaksasi seperti nafas dalam dan yoga (Potter \& Perry, 2005). Dalam hal ini perawat berperan dalam penanganan secara non-farmakologis.

Penggunaan dari kompres hangat dapat membuat sirkulasi darah lancar, vaskularisasi lancar dan terjadi vasodilatasi yang membuat relaksasi pada otot karenan otot mendapat nutrisi yang dibawa oleh darah sehingga kontraksi otot menurun (Eka, Rahmalia dkk, 2017). Pemberian kompres hangat merupakan salah satu tindakan mandiri. Efek hangat dari kompres dapat menyebabkan vasodilatasi pada pembuluh darah yang nantinya akan meningkatkan aliran darah ke jaringan Penyaluran zat asam dan makanan ke sel-sel diperbesar dan pembuangan dari zat-zat diperbaiki yang dapat mengurangi rasa nyeri haid primer yang disebabkan suplai darah ke endometrium kurang, (Anugraheni,2013). 
Hasil penelitian ini Rima Maratun Nida, Defie Septiana Sari Poltekkes Bhakti Mulia Sukoharjo menunjukkan adanya pengaruh kompres hangat terhadap penurunan nyeri dismenorea pada siswi kelas XI di SMK Muhammadiyah Watukelir, dengan nilai p sebesar $0,000(\mathrm{p}<$ $0,05)$.

Berdasarkan penelitian ini disarankan kepada remaja menggunakan teknik relaksasi nafas dalam dan kompres hangat sebagai salah satu alternatif penurunan nyeri dismenore. Sampel sebanyak 32 orang remaja yang dibagi dua pada masing-masing perlakuan dengan waktu pelaksanaan 20 menit. Siswi SMA (Christina D, 2016).

Salah satu cara penatalaksanaan nonfarmakologis untuk mengurangi nyeri menstruasi dengan manajemen sentuhan yaitu pijat endorphine. Pijat Endorphine merupakan sebuah terapi sentuhan/pijatan ringan yang cukup penting diberikan pada wanita yang mengalami nyeri. Hal ini disebabkan karena pijatan merangsang tubuh untuk melepaskan senyawa Endorphine yang merupakan pereda rasa sakit dan dapat menciptakan perasaan nyaman (Kuswandi, 2011).

Hasil penelitian menunjukkan pada 12 mahaissiswi 6 intervnesi dan 6 kelompok control perbedaan yang signifikan antara pijat endorphine terhadap skala nyeri disminore. Sehingga dapat disimpulakan ada pengaruh pijat endorphine terhadap skala nyeri siswi SMA yang mengalami disminore (Elvira M, 2018).

Hasil penelitian menunjukkan bahwa nyeri dismenore sebelum diberikan massage endorphine ada pada kategori nyeri sedang yaitu sebanyak 21 orang (55,3\%). Nyeri dismenore setelah diberikan massage endorphine ada pada kategori nyeri ringan yaitu sebanyak 22 orang (57,9\%). Hasil 
uji Wilcoxon menunjukan bahwa korelasi antara dua variabel adalah sebesar -5.414 dengan signifikasi sebesar 0,000. Hal ini menunjukan bahwa korelasi antara dua variabel rata-rata sebelum dan sesudah adalah kuat dan signifikan. Berdasarkan hasil tersebut dapat disimpulkan bahwa endorphine massage dapat menurunkan nyeri dismenore pada mahasiswi Jurusan Kebidanan Poltekkes Kemenkes Tasikmalaya (Rahayu A, 2017)

Penelitian ini bertujuan Bagi remaja putri yang mengalami Dismenore, Memberikan pengetahuan dan wawasan tentang cara menurunkan nyeri dismenore dengan menggunakan terapi non-farmakologi yaitu kompres air hangat dan endorphine massage.

Penelitian ini dapat memberikan kontribusi sebagai dasar dalam pengembangan asuhan kebidanan khususnya pada remaja putri yang mengalami dismenore dan dapat diaplikasikan pada tatanankebidanan terutama di komunitas (disekolah / dirumah). 


\section{BAB II TINJAUAN PUSTAKA}

\section{A. Remaja dan Menstruasi}

Remaja merupakan periode transisi antara masa anak-anak ke masa dewasa. Di dalam ilmu kedokteran (seperti biologi dan fisiologi), remaja dikenal sebagai suatu tahap perkembangan fisik ketika alat-alat kelamin manusia mencapai kematangan. Hal ini berarti, secara anatomis, alat-alat kelamin maupun organ tubuh yang lain akan memperoleh bentuknya yang sempurna. Masa pematangan fisik berjalan kurang lebih selama dua tahun. Biasanya dihitung mulai haid yang pertama pada wanita dan mimpi basah yang pertama pada pria,(Dahro, 2012). Mulainya haid pertama (menarche) pada seorang wanita ditandai dengan adanya perdarahan secara periodik, yaitu keluarnya darah dari endometrium yang mengalami nekrosis (sel yang mati). Terjadi sekitar 14 hari setelah ovulasi pada siklus 28 hari. Darah haid sebagian besar berasal dari arteri dan vena (Jannah, 2011). Stadium haid atau menstruasi dibedakan menjadi lima, yaitu: stadium menstruasi (3 -7 hari) dimana sel telur yang tidak dibuahi, luruh bersamaan dengan dinding endometrium sehingga timbul perdarahan; stadium proliferasi (7- 9 hari) dimulai sejak berhentinya darah menstruasi sampai hari ke 14; stadium ovulasi, ditandai dengan sekresi LH (Luteinzing Hormone) yang memacu matangnya sel ovum pada hari ke-14 sesudah menstruasi; stadium sekresi, berlangsung selama 11 hari, dimana terjadi pengeluaran progesteron yang membuat kondisi rahim siap untuk mengadakan implantasi; dan stadium 
pra menstruasi, terjadi apabila sel telur tidak dibuahi dan berlangsung selama 3 hari, (Kusmiran,2011). Menstruasi yang normal memiliki siklus tidak kurang dari 24 hari dan tidak melebihi 35 hari, lama haid 3-7 hari dengan jumlah darah selama menstruasi berlangsung tidak melebihi $80 \mathrm{ml}$, ganti pembalut 2-6 kali per hari. Haid normal biasanya 3-5 hari (2-7 hari masih normal), jumlah rata-rata 35 cc (10-80 cc masih dianggap normal), kirakira 2-3 kali ganti pembalut per hari (Purwoastuti dan Walyani, 2015). Gejala-gejala fisik yang umum terjadi selama wanita mengalami menstruasi ialah adanya perubahan berat badan; pembengkakan pada perut, jari, tungkai atau pergelangan kaki, ketidaknyamanan di payudara sebagai akibat pembesaran payudara bila ditekan, akan terasa nyeri dan kaku, sakit kepala, bahkan sebagian wanita mengalami migrain, rasa nyeri dan pegal-pegal pada otot. (Proverawati dan Misaroh, 2009).

Menstruasi adalah keluarnya darah dari rahim melalui vagina dan keluar dari tubuh seorang wanita setiap bulan selama masa usia subur (Faizah,2000). Menstruasi adalah peristiwa keluarnya darah dari vagina karena meluruhnya lapisan dinding rahim yang banyak mengandung pembuluh darah (endometrium), pada saat sel telur tidak dibuahi. Sel telur ( yang hanya dimiliki oleh perempuan) hanya keluar sebulan sekali, dan apabila tidak ada pembuahan, misalnya melalui hubungan seksual, maka 14 hari kemudian sel telur itu akan gugur bersama dengan darah pada lapisan dinding rahim yang sebelumnya menebal. Hal ini biasanya akan berlangsung kurang lebih 28 hari (antara 21-35 hari). 
Siklus menstruasi dapat dipengaruhi oleh kondisi tertentu, seperti stress, pengobatan dan latihan olahraga. Pada masa remaja biasanya siklus menstruasi belum teratur, namun setelah dalam kurun waktu tertentu akan teratur. Menstruasi merupakan bagian dari proses reguler yang mempersiapkan tubuh wanita setiap bulannya untuk kehamilan (Keikos, 2007).

\section{B. Dismenorea}

\section{Pengertian Dismenorea}

Dismenorea merupakan nyeri pada daerah panggul akibat menstruasi dan produksi zat prostaglandin. Dismenorea terbagi menjadi dua yaitu dismenorea primer dan sekunder. Dimenorea primer masih belum jelas penyebabnya kemungkinan disebabkan rasa sakit oleh iskemia akibat kontraksi kuat dari muskulus rahim yang terjadi selama harihari pertama menstruasi. Dismenorea sekunder disebabkan selain proses menstruasi dan produksi prosaglandin, ditemukannya kelainan gynekologi seperti penyakit radang panggul, endometriosis, fibroid, tumor ovarium dan kehadiran alat kontrasepsi intrauterine (Scambler, Annette 1993).

Dismenore merupakan kondisi normal khususnya pada wanita yang sedang mengalami menstruasi, namun nyeri menstruasi dapat muncul berlebihan karena dipengaruhi oleh beberapa faktor seperti fisik, psikis seperti stres dan hormon prostaglandin yang tinggi. Hormon prostaglandin yang disekresi berlebihan akan berdifusi ke dalam jaringan endometrial yang akan meningkatkan amplitudo dan frekuensi kontraksi uterus, sehingga 
mengakibatkan iskemia uterus dan hipoksia pada jaringan uterus, dan disintegrasi endometrium, perdarahan serta kram abdomen bawah yang merangsang nyeri saat menstruasi (Morgan \& Hamilton, 2009).

Nyeri sebelum dan selama menstruasi merupakan penyebab umum bagi banyak perempuan. Masalah dapat berkurang setelah adanya non-steroid anti-inflammatory drugs (NSAID). Terapi ini sangat efektif untuk dismenorea sehingga dapat diberikan kepada seorang wanita yang tidak sembuh setelah diberikan asam mefenamat (ponstan) atau naproxen sodium (naprogesic). Dismenorea sekunder menjadi adalah nyeri panggul patologi sebagai fibroid atau endometriosis (Chapman dan Hall, 1996).

\section{Epidemiologi Dismenorea}

Dismenorea adalah ginekologi yang sering terjadi sekitar 30-75\% wanita mengalami dismenorea. Secara umum didapatkan lebih dari 50\% wanita. Biasanya kejadian tergantung pada usia wanita yang telah dtetapkan sekitar $10 \%$ wanita yang mengalami dismenorea sering mengakibatkan tidak masuknya wanita 1-3 hari disekolah maupun dipekerjaan. Angka kejadian dismenorea dilndonesia belum ada secara detail. Sebenarnya angka kejadiannya cukup tinggi. Namun, yang berobat ke dokter hanya sedikit yaitu 1-2 \% (Sylvia dan Lorraine, 2006). Dismenore dapat diklasifikasikan menjadi 2 yaitu dismenore primer dan dismenore sekunder. Dismenore primer yaitu nyeri haid yang dimulai 2-3 tahun setelah perempuan mengalamai menarche, dijumpai tanpa kelainan pada 
alat-alat genetalia yang nyata, sedangkan dismenore sekunder yaitu nyeri haid yang disebabkan oleh kelainan ginekologi seperti salpingitis kronika, endometriosis, adenomiosis uteri, stenosis servistis uteri, dan lain-lain (Prawirohardjo \& Wiknjosastro 2008)

\section{Etiologi Dismenorea}

a. Dismenorea Primer

Banyak teori telah dikemukakan untuk menerangkan penyebab dismenorea primer, tetapi patofisiologinya belum jelas dimengerti. Rupanya beberapa faktor memegang peranan sebagai penyebab dismenorea primer antara lain :

1) Faktor endokrin.

Teori ini tidak dapat menerangkan fakta mengapa timbul rasa nyeri pada perdarahan disfungsional anovulatoar, yang biasanya bersamaan dengan kadar estrogen yang berlebihan tanpa adanya progesteron.

2) Faktor kejiwaan

Pada gadis-gadis yang secara emosional tidak stabil dan apabila jika tidak mendapat penerangan yang baik tentang proses menstruasi, akan mudah timbul dismenorea.

3) Faktor konstitusi

Faktor ini sangat erat hubungannya dengan faktor tersebut diatas, dapat menurunkan ketahanan rasa nyeri. Faktor-faktor seperti anemia dan penyakit menahun, dan sebagainya dapat mempengaruhi timbulnya dismenorea. 
Anemia adalah defisiensi eritrosit atau hemoglobin atau dapat keduanya hingga menyebabkan kemampuan mengangkut oksigen berkurang. Sebagian besar penyebab anemia adalah kekurangan zat besi yang diperlukan untuk pembentukan hemoglobin, sehingga disebut anemia kekurangan zat besi. Kekurangan zat besi ini dapat menimbulkan gangguan atau hambatan pada pertumbuhan baik sel tubuh maupun sel otak dan dapat menurunkan daya tahan tubuh seseorang, termasuk daya tahan tubuh terhadap rasa nyeri (Hurlock, 2007).

4) Faktor alergi

Teori ini dikemukakan setelah memperhatikan asosiasi antara dismenorea dengan urtikaria, migraine atau asma bronkhiale. Smith menduga penyebab bahwa sebab alergi adalah toksin haid (Wiknjosastro, 2005).

b. Dismenorea Sekunder

Dismenorea sekunder dapat terjadi setelah haid pertama, tetapi yang paling sering muncul di usia 20 - 30 tahun, setelah bertahun - tahun mengalami siklus tanpa nyeri. Dismenorea terjadi karena mempunyai etiologi organik. Anamnesa dan pemeriksaan perlu dilengkapi dengan USG dan atau visualisasi langsung di laparoskopi. Infeksi panggul, perlengketan, massa ovarium atau tuba patologi, fibromyomata, endometriosis dan adenomysis adalah beberapa penyebab yang lebih umum dari dismenorea sekunder. Jika terdapat 
salah satu dari kondisi tersebut maka pengobatan khusus.

Dismenore adalah gangguan aliran darah menstruasi atau nyeri menstruasi, (Proverawati dan Misaroh, 2009). Disminore berdasarkan jenisnya dibedakan menjadi dua, yaitu disminore primer, dimana nyeri menstruasi yang tidak disertai dengan kelainan organ reproduksi; dan disminore sekunder, nyeri menstruasi karena adanya kelainan organ reproduksi (endometriosis, fibrods). Pada umumnya disminore terjadi pada perut bagian bawah, kadang menyebar ke sekitarnya, Kadang kadang disertai mual, muntah, sakit kepala dan diare. Ada beberapa faktor yang menyebabkan terjadinya disminore, antara lain yaitu faktor hormonal, faktor psikis, faktor kejiwaan, faktor resiko. Menentukan nyeri disminorea, disini menggunakan skala penilaian numerik (Numerical Rating Scale, NRS) yang digunakan sebagai pengganti alat pendeskripsi kata, dengan menggunakan skala 0-10.

\section{Kompres Hangat dan Endorphine Massage}

Secara umum penanganan nyeri dismenorea terbagi dalam dua kategori pendekatan farmakologis dan non farmakologis. Secara farmakologis nyeri dapat ditangani dengan terapi analgesik yang merupakan metoda paling umum digunakan untuk menghilangkan nyeri (Dwi Christina, 2016). Menurut penelitian yang dilakukan oleh Astrida Rakhma tahun 2013, upaya penangan dismenorea secara non farmakologi terdiri dari istirahat total atau tidur, teknik distraksi, kompres hangat, pengobatan 
herbal, posisi knee chest, teknik menarik nafas dalam, dan pemijatan.

Nyeri dismenore jika tidak segera diatasi akan mempengaruhi fungsi mental dan fisik individu sehingga mendesak untuk segera mengambil tindakan/terapi secara farmakologis atau non farmakologis. Terapi secara farmakologis salah satunya dengan pemberian obat-obat analgesik. Obat golongan NSAID (Nonsteroidal Antiinflammatory Drugs) dapat meredakan nyeri ini dengan cara memblok prostaglandin yang menyebabkan nyeri. Pengobatan dengan menggunakan NSAID memiliki efek samping yang berbahaya terhadap sistem tubuh lainnya (nyeri lambung dan resiko kerusakan ginjal). Terapi non farmakologis antara lain pengaturan posisi, teknik relaksasi, manajemen sentuhan, manajemen lingkungan, distraksi, dukungan perilaku, imajinasi, kompres dan pemberian ramuan herbal (Kuswandi, 2011).

Pemberian kompres hangat merupakan salah satu tindakan mandiri. Efek hangat dari kompres dapat menyebabkan vasodilatasi pada pembuluh darah yang nantinya akan meningkatkan aliran darah ke jaringan Penyaluran zat asam dan makanan ke sel-sel diperbesar dan pembuangan dari zat-zat diperbaiki yang dapat mengurangi rasa nyeri haid primer yang disebabkan suplai darah ke endometrium kurang, (Natali,2013).

Penggunaan dari kompres hangat dapat membuat sirkulasi darah lancar, vaskularisasi lancar dan terjadi vasodilatasi yang membuat relaksasi pada otot karenan otot mendapat nutrisi yang dibawa oleh darah sehingga kontraksi otot menurun (Eka, Rahmalia dkk, 2017). Pemberian kompres hangat memakai prinsip 
pengantaran panas melalui cara konduksi yaitu dengan menempelkan bulibuli panas pada perut sehingga akan terjadi perpindahan panas dari buli-buli panas ke dalam perut, sehingga akan menurunkan nyeri pada wanita dengan dismenore primer, karena pada wanita dengan dismenore ini mengalami kontraksi uterus dan kontraksi otot polos (Anugraheni dan Wahyuningsih, 2013).

Salah satu cara penatalaksanaan nonfarmakologis untuk mengurangi nyeri menstruasi dengan manajemen sentuhan yaitu pijat endorphine. Pijat Endorphine merupakan sebuah terapi sentuhan/pijatan ringan yang cukup penting diberikan pada wanita yang mengalami nyeri. Hal ini disebabkan karena pijatan merangsang tubuh untuk melepaskan senyawa Endorphine yang merupakan pereda rasa sakit dan dapat menciptakan perasaan nyaman (Kuswandi, 2011).

Selama ini endorphine sudah dikenal sebagai zat yang banyak manfaatnya. Beberapa diantaranya adalah, mengatur produksi hormon pertumbuhan dan seks, mengendalikan rasa nyeri serta sakit yang menetap, mengendalikan perasaan stres, serta meningkatkan sistem kekebalan tubuh. Endorphine dalam tubuh bisa dipicu munculnya melalui berbagai kegiatan, seperti pernapasan yang dalam dan relaksasi, serta meditasi (Haruyama, 2011).

Pijat endorphine pertama kali dilakukan seorang ahli kebidanan, Constance Palinsky, tergerak untuk menggunakan endorphine untuk mengurangi atau meringankan rasa sakit pada ibu yang akan melahirkan. Diciptakanlah pijat endorphine, yang merupakan teknik sentuhan serta pemijatan ringan, yang dapat menormalkan denyut jantung dan tekanan darah, serta meningkatkan kondisi rileks dalam tubuh 